\title{
2012/42
}

\section{Peer group and distance: when widening university participation is better}

Berardino Cesi and Dimitri Paolini

\section{DISCUSSION PAPER}

Center for Operations Research and Econometrics

Voie du Roman Pays, 34

B-1348 Louvain-la-Neuve

Belgium

http://www.uclouvain.be/core 


\title{
CORE DISCUSSION PAPER \\ $2012 / 42$
}

\section{Peer group and distance: when widening university participation is better}

\author{
Berardino CESI ${ }^{1}$ and Dimitri PAOLINI ${ }^{2}$
}

October 2012

\begin{abstract}
We analyze the welfare effect of allowing a new university in a local area where another university is already operating. We use a two-city model in which individuals, whose education depends on the average peer ability (peer group effect), can sort across cities by facing a mobility cost. Com- paring monopoly with a two-university system we find that introducing the second university is always welfare improving. We obtain a symmetric Nash equilibrium for every mobility costs and asymmetric Nash equilibria only for sufficiently low mobility costs. In particular, in the symmetric scenario both universities have the same peer groups (lower than the peer group under monopoly) and the same number of students. The asymmetric scenario instead is such that the "top" ("bottom") university has a peer group higher (lower) than the monopolistic one. Moreover, we find that the symmetric scenario always induces the highest welfare. After checking for equilibrium refinements we find that asymmetric equilibria are never strong Nash whereas the symmetric equilibrium is strong Nash only for sufficiently high mobility costs.
\end{abstract}

Keywords: peer group quality, mobility costs, universities.

JEL classification: I21, I23

\footnotetext{
${ }^{1}$ University of Rome Tor Vergata, Department of Economics and Finance, I-00133 Rome, Italy. E-mail: berardino.cesi@uniroma2.it

${ }^{2}$ Università of Sassari, CRENoS and DiSEA, I-07100 Sassari, Italy. E-mail: dpaolini@uniss.it

We wish to thank Antonio Vezzani, Fausto Galli, Luca Deidda, Pierre Pestieau, Tito Pietra, Vincenzo Scoppa and Xavier Wauthy for their helpful comments. We also thank the audience at 2nd Workshop 'Industrial Organization: Theory, Empirics and Experiments', Otranto 2011. The second author acknowledges the financial support of MIUR-PRIN 2008 and Fondazione Banco di Sardegna. The first author thanks the "Visiting Professor Program" at the University of Sassari (CRENoS and DEIR).
} 


\section{Introduction}

In the last decades empirical evidence confirms a proliferation of universities in Europe. ${ }^{1}$ A recent publication by the British Department for Innovation, Universities and Skills, "A New University Challenge; Unlocking Britain's Talent", shows the intention of the British government to rise the number of local institutions as policy to widen higher education participation to socially excluded individuals. $^{2}$ In the document it reads: "Over and above their contribution to economic regeneration and development, universities and other higher education providers are seen as making a real difference to the cultural life of our towns and cities. So it is not surprising that increasing numbers of towns and cities are seeking to offer higher education. We want to make the process of gaining a higher education campus more open and more transparent."

Such a policy is based on the empirical evidence that geographical distance and peer group quality are respectively a barrier and a strengthening to the higher education participation. ${ }^{3}$

We study the welfare implications of introducing a new university in a twocity scenario where only one university is active and students' human capital positively depends on own and average ability (peer group effect). We find that one more university is always welfare improving, especially when leading to an equal two-university system.

We assume that, in each city, students are uniformly and independently distributed according to their ability. They are free to attend university (if any) in their city or in the other, with the second option implying a mobility cost. The two universities are then endogenously differentiated only according to students' average ability and number. We find both a symmetric and asymmetric Nash equilibria. In the former, existing for every mobility cost, both universities have the same peer group effects (lower than the monopolistic peer group) and the same number of students. In the latter, existing only for low mobility costs, peer groups effects are different, with the one in the "top" ("bottom") university higher (lower) than the monopolistic one. Although the asymmetric system is

\footnotetext{
${ }^{1}$ In a recent empirical study Daraio et al. (2010) find that the number of universities shows an acceleration after 1970 in Finland, France, Germany, Hungary, Italy, Netherlands, Norway, Portugal, Spain, Switzerland and the UK. This phenomenon is strong in Italy where 27 universities have been created between 1982 and 2004.

${ }^{2}$ According to this official document, the UK government's strategy aims to create up to 20 new centers of higher education (HE) by 2014.

${ }^{3}$ Empirical evidence regarding to the existence of the peer group at the university is provided for the US by Sacerdote (2001), Zimmerman (2003), Arcidiacono and Nicholson (2005), Hoxby and Weingarth (2005), Aricidiacono et al. (2010)), for Italy by De Giorgi, Pellizzari and Redaelli (2006) and Brunello, De Paola and Scoppa (2010), for China by Ding and Lehrer (2007) and for South Korea by Kang (2007). The effect of the geographical distance on the higher university participation has been recently confirmed by Frenette (2004, 2005 and 2009), Sà et al. (2006), Gibbons and Vignoles (2009), Speiss and Wrohlich (2010) and Kenyon (2010). Frenette (2009) shows that the creation of a local university in Canada is associated with a large increase in university attendance among local youth in each affected city. Speiss and Wrohlich (2010) find that in Germany an increase in the distance between home and university is associated with a lower participation. Gibbons and Vignoles (2009) show that distance is the strongest factor influencing university choice in Britain.
} 
peer group maximizer, we obtain that the symmetric system induces the highest welfare. When the mobility cost is high, moving is so costly that none leaves his town therefore, given the endogeneity of the peer group, asymmetric equilibria cannot exist. When replacing monopoly with a symmetric system, individuals remaining in the ex-monopolist are worse off because they receive a lower peer group. High ability individuals, that would have switched city to attend the monopolist, are better off in the "new" university in their city only for high mobility costs. The new university, though with the lowest quality, allows the least able individuals (left unskilled by the monopolist) to get skilled without costs. Overall, the benefit guaranteed to the new skilled offsets the loss for the individuals that would have studied in the "better" monopolistic university. When replacing a monopolistic university with an asymmetric system, all individuals are better off. In particular, those remaining in the ex-monopolist receive a higher peer group without paying the mobility cost. Able individuals, usually going to the monopolist but that, with two universities, choose the university in their city, are also better off because the peer group given up in the better university is even greater than the monopolistic one. Finally, when we compare symmetric and asymmetric equilibria, we find that the individuals living in the city of the "better" university (ex-monopolist) unambiguously benefit more from the asymmetric system because they receive a higher peer group, without mobility costs. The new skilled instead prefer the symmetric system because it induces a higher peer group in their city. Although able individuals switching city to attend the "better" university prefer the asymmetric scenario, all the welfare losses in the symmetric system are offset by the benefits of the new skilled individuals.

Most of the literature focusing on the peer group effect at university introduces an explicit competition among institutions (see the seminal contribution in Del Rey (2001), followed by De Fraja and Iossa (2002) and most recently Del Rey and Wauthy (2006), Gautier and Wauthy (2007), and Grazzini et al. (2010)). In Del Rey (2001) and De Fraja and Iossa (2002) the peer group quality is explicitly driven by the competition among universities that set an admission ability standard and students choose institution according to mobility costs. As in De Fraja and Iossa (2002), when mobility costs are not too high we find asymmetric equilibria in which only one university induces the highest peer group effect. Differently from this literature, we rule out competition and only focus on the welfare effect from the introduction of a new university. We show that a new university may allow the ex-monopolist to improve its peer group by becoming de facto the "better" university of an asymmetric system. We therefore show that the government itself may increase welfare and keep a "top" university by simply permitting a new university closes to the monopolist without necessarily inducing or enforcing an explicit competitive behavior. In our model the main determinant of the welfare improvement is the sorting behavior of the students mainly driven by the reduction in the mobility costs due to the presence of a new university. Indeed, our policy implication is that a new university should be permitted especially in zones where mobility costs are high (for any reasons like lack of material and immaterial infrastructures) without 
necessarily inducing local institutions to compete each other. Differently from De Fraja and Iossa (2002) but in line with Gautier and Wauthy (2007) and Del Rey and Wauthy (2006), we propose a refinement of the equilibrium concept by solving the model also for strong Nash equilibria. We find that asymmetric equilibria are never strong Nash whereas the symmetric equilibrium is strong Nash only for sufficiently high mobility costs. Our paper also belongs to the literature studying the link among geographic constraints, segregation and human capital accumulation (see Mookherjee, Napel and Ray (2010a, 2010b) among the most recent papers). They find a reduction in the mobility costs being welfare increasing if the segregated equilibrium is majority-skilled. Interpreting a new university as a mobility cost reducing policy, we obtain that a lower mobility cost is welfare improving when the segregated equilibrium is minority-skilled, that is the opposite of what they predict. ${ }^{4}$

The paper is organized as follows. Section 2 introduces the model. Section 3 analyzes the case with a monopolistic university while in Section 4 we study a two-university system. In Section 5 we proceed with the welfare analysis. Section 6 draws the main conclusions.

\section{The model}

We consider a spatial two-city $(j=A, B)$ model in which each city may host one university that "produces" graduates. Individuals, $i$, living in each city are uniformly and independently distributed according to their innate ability $\theta_{i} \in[0,1]$, with the total population in each city normalize to 1 . The utility of each individual $i$, attending university $j$, is: ${ }^{5}$

$$
U_{i}^{j}\left(\bar{\theta}_{j}\right)=\theta_{i}\left(1+\bar{\theta}_{j}\right)
$$

where $\bar{\theta}_{j}$ measures the average ability at the university $j$ that henceforth will be also called peer group effect. The distance between universities (cities) is normalize to 1 . A student located in $j$ has no mobility cost of attending university $j$, but he faces a liner cost $t$ if attending $-j \neq j$. The (net of $t$ ) utility in (1) is in line with the main assumptions on human capital accumulation, that are, $U_{\theta_{i}}^{j}>0, U_{\bar{\theta}_{j}}^{j}>0$ and $U_{\bar{\theta}_{j} \theta_{i}}^{j}>0$. The first derivative simply assumes that utility increases in the ability. The second derivative introduces the role of the

\footnotetext{
${ }^{4}$ Although Mookherjee, Napel and Ray (2010, 2010b) don't explicitly introduce the peer group quality, they use a spatial analysis to study how human capital depends on the individual location used as proxy for the cost of acquiring skill. They study the welfare effect of a reduction in the mobility cost by comparing a segregated with an unsegregated equilibrium. According to their jargon, we can interpret our monopolistic scenario as a segregated equilibrium because, as in their model, our "marginal" individual left unskilled by the monopolist gets instead skilled with a new university. Moreover, in their model a majority-skilled equilibrium is defined according to the "global fraction of skilled labor" that in our model can be simply translated in the fraction of individuals attending university. Thus, our monopolistic equilibrium is consistent with their definition of minority-skilled.

${ }^{5}$ We are implicitly assuming no drop-out and an over simplified labour market in which the wage is equal to the human capital.
} 
peer group effect: utility (as proxy of human capital) increases in the average ability at the university. The positive cross derivative in the last term implies that the peer effect becomes more effective in increasing utility (producing human capital) as the level of the innate ability increases, or in other words high ability students benefit more from a higher peer group effect. This assumption follows the seminal contribution by Epple and Romano (2008) and is also in line with the empirical evidence in Hoxby and Weingarth (2005), Ding and Lehrer (2007), Kang (2007) and Brunello, De Paola and Scoppa (2010). ${ }^{6}$

Mobility costs are one of the main economic constraints for students attending university. Some universities, in fact, include these costs when determining the full cost of attendance and the eligibility for financial aids. In line with the literature on human capital accumulation (e.g., Banerjee and Newman 1993; Galor and Zeira 1993; Maoz and Moav 1999; Mookherjee and Ray 2003; Mookherjee, Napel and Ray 2009, 2010) we assume that mobility cost is the only constraint. When an individual $i$ does not attend the university is defined unskilled, $u$, and his utility is:

$$
U_{i, u}=\theta_{i}
$$

We keep the labour market as simple as possible because we aim to focus on the relationship between the peer group and the mobility cost. For the rest of the paper we consider the peer group effect (average ability) as proxy for the university quality, therefore we will equivalently use these two terms. ${ }^{7}$

\section{Monopolistic University}

In this section we study the scenario with only one university, equivalently called monopolistic university henceforth. Assume this university is located in the city $A$. In this scenario each student can only choose between going to the monopolistic university and being unskilled. It is straightforward to state that the monopolistic university (denoted by $A$ ) is attended by all the individuals located in $A$ plus some students from $B$. Students living in $A$ are clearly better off by attending the costless university rather than being unskilled. Students living in $B$, instead, face linear mobility costs when going to the university in the other city. Once faced the mobility costs, individuals can freely move between cities, therefore the peer group is endogenous. Let's denote $\theta_{M}$ as the average ability at the monopolistic university, this is defined in the following Lemma:

\footnotetext{
${ }^{6}$ Hoxby and Weingarth (2005) in particular find a positive cross derivative in case of higher ability peers. For the Italian case, Brunello, De Paola and Scoppa (2010) prove that peer effects are positive and statistically significant for students enrolled in engineering, math and natural science and close to zero in the humanities. Less recent evidence is also provided by Sacerdote (2001) and Zimmerman (2003).

${ }^{7}$ This simplification is in line with the main existing literature considering the peer group quality as one of the main component of the university's objective function, together with Prestige and Research (De Fraja and Iossa, 2002) and Research (Del Rey 2001).
} 
Lemma $1 \theta_{M}$ is a concave function in the mobility cost for every $0 \leq t \leq 0.5$, increasing for low mobility costs and decreasing for high mobility costs.

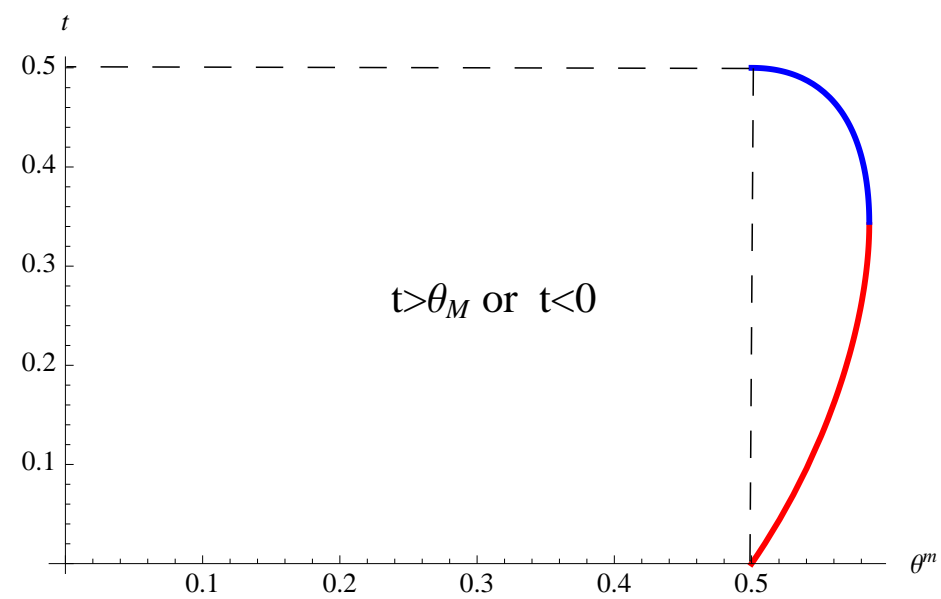

Figure 1

Since all individuals living in $A$ go to the university regardless the mobility cost, the trend in the figure 1 is due to the sorting behavior of the able individuals in $B$. When the mobility cost is too high none from $B$ find it profitable switching to $A$. For a "reasonable" mobility cost instead this sorting behavior matters. A rise in the mobility cost increases the lowest ability such that individuals from $B$ find it profitable attending the university $A$. For a moderate rise in the mobility costs, only less able individuals find it too costly moving to $A$. When, instead, the rise in the mobility cost is sufficiently strong, the same effect also occurs for the high ability individuals and the average ability at the monopolistic university $(A)$ starts to decrease. For a more rigorous and analytical analysis of the trend in the figure 1 see the Appendix.

\section{Two-University system}

Let's assume the introduction of a new university in the city $B$ (university $B$ henceforth). In this scenario individuals sort across universities according to the mobility costs and the peer groups, here denoted by $\theta_{A}^{d}$ and $\theta_{B}^{d}$. What matters for their choice, other than mobility costs, is the university they receive the higher peer group quality from. The following Proposition characterizes the Nash equilibria of the two-university system. ${ }^{8}$

Proposition 1 There exist two asymmetric equilibria: (i) $\theta_{A}^{d *}=\frac{1+t}{2}, \theta_{B}^{d *}=$ $\frac{1+t}{4}-\frac{1}{4} \sqrt{t^{2}-6 t+1}$, (ii) $\theta_{A}^{d *}=\frac{1+t}{2}, \theta_{B}^{d * *}=\frac{1+t}{4}+\frac{1}{4} \sqrt{t^{2}-6 t+1}$ for every $t \in[0,3-2 \sqrt{2}]$ and (iii) a symmetric equilibrium, $\tilde{\theta}_{A}^{d}=\tilde{\theta}_{B}^{d}=\frac{1}{2}$, for every $t$.

${ }^{8}$ We recall that $t \leq 1$. 
The asymmetric equilibria survive only when the mobility costs are not too high. Let us analyze the asymmetric equilibrium (i). ${ }^{9}$ The least able individual (defined as $\widehat{\theta}_{B}=\frac{t}{\left(\theta_{A}^{d}-\theta_{B}^{d}\right)}$ in 17), living in $B$ but preferring university $A$ to $B$, in the equilibrium (i) becomes $\widehat{\theta}_{B}=\frac{4 t}{t+\sqrt{-6 t+t^{2}+1}+1}$, that is increasing in the mobility cost. When the mobility cost increases, the peer group $\theta_{A}^{d *}$ rises and the same does $\widehat{\theta}_{B}$. In words, when the mobility cost increases, the peer group in the university $A$ must increase to offset this higher cost and still attract individuals from $B$. At this higher mobility cost, individuals from $B$ need to be abler and abler to afford the university $A$. When mobility costs are sufficiently high (here $t>3-2 \sqrt{2}$ ) the asymmetric equilibria do not survive because each individual is better off in the university in its city. In this case moving is so costly that no individual leaves, therefore the average abilities associated to high mobility costs must be equal. The general massage here is that increasing individuals' mobility with the introduction of a new university may lead to polarization if more able individuals are more likely to move and peer group effects matter.

\section{$5 \quad$ Welfare analysis}

In this section we study the welfare effect from allowing a new university in $B$. We define the welfare as the unweighted sum of the individual utilities, net of the mobility costs:

$$
W=\int_{\theta^{-}}^{\theta^{+}} U_{i}^{j}\left(\bar{\theta}_{j}\right) d \theta
$$

The values $\theta^{-}$and $\theta^{+}$depend on which group of individuals we consider, and $\bar{\theta}_{j}$ is the peer group (if any) each individual benefits from. To ease the welfare analysis the following Lemma compares the peer group effects obtained in the duopolistic and monopolistic case. ${ }^{10}$

Lemma $2 \theta_{B}^{d *}<\theta_{B}^{d * *}<\theta_{M}<\theta_{A}^{d *}$ and $\theta_{M}>\tilde{\theta}_{A}^{d}=\tilde{\theta}_{B}^{d}>\theta_{B}^{d * *}>\theta_{B}^{d *}$.

Lemma 2 shows that symmetric universities induce a lower peer group quality than the monopolist that, in turn, induces a higher quality than the "bottom" university in the asymmetric system. However, only an asymmetric (unequal) system produces the highest peer group. The main intuition is that, with an university in $B$, individuals from $B$ that go to the ex-monopolist (university $A$ ) must have an ability sufficiently high to induce the peer group in $A$ to overcome the mobility cost. For the less able individuals that would have attended the monopolist, but prefer the university $B$ in the new scenario, the save in

\footnotetext{
${ }^{9}$ The same arguments hold for the equilibrium (ii).

${ }^{10}$ Given the result in Lemma 1 and Proposition 1 we restrict the analysis to the range $t \leq 3-2 \sqrt{2}$. Also, in the rest of the analysis we do not consider $t=0$ because it would imply $\theta_{M}=\theta_{A}^{d *}=0.5, \theta_{B}^{d *}=0, \theta_{B}^{d * *}=0.5$ and (as it will be clear in what follows) always the same welfare in the three types of equilibria.
} 
the mobility cost overcomes the loss from the lower average ability in the new university (shared with the less able individuals of their city).

Let us now define $W_{M}, W_{S}$ and $W_{a}$ as the welfare with respectively monopoly, symmetric and asymmetric universities. The main result of the paper is stated in the following proposition.

Proposition $2 W_{S}>W_{a}>W_{M}$ for every $t \in\left(0,3-2 \sqrt{2}\right.$ and $W_{S}>W_{M}$ for every $t \in(0,0.5)$

We find that, when mobility costs and peer group effects are the main drivers of the individuals' choice, a new university is welfare improving. Both asymmetric (unequal) and symmetric (equal) systems induce more welfare than a monopolist, thought the monopolistic university guarantees more quality than the symmetric system and the new university.

Consider the comparison between $W_{S}$ and $W_{M}$. Given $\theta_{M}>\tilde{\theta}_{A}^{d}=\tilde{\theta}_{B}^{d}=0.5$, individuals left unskilled by the monopolist (with ability $0 \leq \theta<\frac{t}{\theta_{M}}$ ) benefit from the new university because they get skilled without mobility costs. On the other hand, students remaining in $A$ are worse off because they benefit from a lower peer group. However, for the abler individuals in $B$ that would go to the monopolist but choose the new university $B$ in the symmetric scenario, the change in the total welfare is ambiguous. These individuals (with ability $\frac{t}{\theta_{M}} \leq \theta \leq 1$ ) benefit from the symmetric system only when the mobility cost is sufficiently high. The intuition is simple, they are better off in the university in their city only when the save on mobility costs offsets the loss from the lower peer group. In particular, if we denote their welfare from attending the monopolist $\left(\widetilde{W}^{M}\right)$ and the university $B\left(\widetilde{W}^{B}\right)$ as:

$$
\begin{gathered}
\widetilde{W}^{M}=\int_{\frac{t}{\theta_{M}}}^{1}\left(U^{M}\left(\theta_{M}\right)-t\right) d \theta \\
\widetilde{W^{B}}=\int_{\frac{t}{\theta_{M}}}^{1} U^{B}\left(\tilde{\theta}_{B}^{d}\right) d \theta
\end{gathered}
$$

it is straightforward to see that $\widetilde{W}^{M} \leq \widetilde{W}^{B}$ for every $\frac{\theta_{M}\left(2 \theta_{M}-1\right)}{2 \theta_{M}+1} \leq t .{ }^{11}$

Overall the welfare losses for the individuals in $A$ and for the able individuals in $B$ (when $t<-\frac{\theta_{M}-2 \theta_{M}^{2}}{2 \theta_{M}+1}$ ) are offset by the welfare improvement for the (less able) individuals that would have remained unskilled (in $B$ ) without the new university. However, see that when the mobility costs are sufficiently high $\left(-\frac{\theta_{M}-2 \theta_{M}^{2}}{2 \theta_{M}+1}<t\right)$ even able individuals in $B$, that would have gone to the monopolist, are better off in the symmetric system. Since the peer group of the monopolist is unambiguously higher than the peer group of the symmetric case, then we confirm that the mobility cost is the main driver of the welfare effect when another university is introduced.

The first part of Lemma 2 implies that the monopolist becomes de facto the "top" university of an asymmetric system. Allowing another university in

${ }^{11}$ With $\frac{\theta_{M}\left(2 \theta_{M}-1\right)}{2 \theta_{M}+1}<0.5$. 
the near city allows the monopolist to improve its peer group because it loses the less able individuals previously coming from $B$. This result replicates the outcome obtained by the literature on competition among universities where an "elite" university may maximize the peer group effect and induce a welfare improvement. The main difference with this literature is that we obtain the same result without inducing universities to compete each other.

However, although the asymmetric system induces a peer group higher than the symmetric one, the former induces a lower welfare $\left(W_{a}<W_{S}\right)$. To clarify this result we compare the welfare changes for the original populations in $A$ and $B$. The population in $A$ is clearly better off with an asymmetric system because $\theta_{A}^{d *}>\tilde{\theta}_{A}^{d}$ without mobility costs. The population in $B$, instead, in the asymmetric equilibrium is divided in two groups: individuals going to $A$ (with ability $\frac{t}{\theta_{A}^{d *}-\theta_{B}^{d *}} \leq \theta \leq 1$ ) and individuals staying put (with ability $0 \leq \theta \leq$ $\left.\frac{t}{\theta_{A}^{d *}-\theta_{B}^{d *}}\right)$. The individuals in the first group are better off in the asymmetric case because they are so able to offset the mobility cost when switching. ${ }^{12}$ On the other hand, not surprisingly, the low ability individuals in the second group are better off in the symmetric system because they benefit from a higher peer group $\left(\tilde{\theta}_{B}^{d}>\theta_{B}^{d * *}>\theta_{B}^{d *}\right)$. However, the total welfare for the entire population $B$ is higher in the symmetric system, in fact, after simple substitutions we obtain:

$$
\int_{\overline{\theta_{A}^{d *}-\theta_{B}^{d *}}}^{1}\left(U^{A}\left(\theta_{A}^{d *}\right)-t\right) d \theta+\int_{0}^{\overline{\theta_{A}^{d *}-\theta_{B}^{d *}}} U^{B}\left(\theta_{B}^{d *}\right) d \theta<\int_{0}^{1} U^{B}\left(\tilde{\theta}_{B}^{d}\right) d \theta
$$

The left hand side of (6) denotes the welfare for the population $B$ under the asymmetric equilibrium, with the first and the second term identifying the welfare of the leaving and the remaining individuals. The right hand side denotes the welfare in the symmetric equilibrium. Thus, we conclude that the welfare improvement allowed by the asymmetric system to the individuals studying in $A$ (living there or coming from $B$ ) is offset by the loss induced to the (least able) individuals in $B$. It is easy to check that all these arguments (and inequalities) also hold for the asymmetric equilibrium (ii), therefore we omit the analysis.

\section{$6 \quad$ Equilibrium refinements}

In the previous sections we solve the model only for Nash equilibria. This means that no individual unilaterally deviates from his own equilibrium strategy. However, if we allow individuals to form coalitions, we cannot exclude that individuals and/or students form coalitions that optimally choose strategies different from each individual equilibrium strategy. In the common jargon such a coalition is defined deviating coalition. According to the main literature a Nash

\footnotetext{
${ }^{12}$ With simple algebra it is possible to show that $\int_{\frac{\theta_{A}^{d *}-\theta_{B}^{d *}}{1}}\left(U^{A}\left(\theta_{A}^{d *}\right)-t\right) d \theta>$ $\int_{\frac{1}{\theta_{A}^{d *}-\theta_{B}^{d *}}}^{1} U^{B}\left(\tilde{\theta}_{B}^{d}\right) d \theta$
} 
equilibrium is strong Nash when no deviating coalition exists. In this section we check for this equilibrium refinement. The following propositions give the main results.

Proposition 3 The symmetric equilibrium is strong Nash only for $t>0.086$.

When the mobility costs are sufficiently high, no profitable deviating coalition exists because the mobility costs always offset the benefit from the average ability received once switched university.

Proposition 4 The asymmetric equilibria are never strong Nash.

The Proposition 4 shows that when students are polarized over two asymmetric universities there exists at least a deviating coalition. This is the case for the coalition composed of all the individuals from $B$ that go to $A$ in the asymmetric equilibrium. Should they form such a coalition, the save on mobility costs (from going back to $B$ ) would offset the lost of the higher average ability in the "top" university.

\section{$7 \quad$ Main conclusions}

This paper starts from two empirical results: $i)$ the existence of the peer group effect at the higher education, and ii) the proliferation of universities, especially in Europe. We link these two results and theoretically investigate the effect of introducing a new university when individuals choose institutions according to the peer group effect, innate ability and mobility costs. We compare a monopolistic system with a two-university scenario in which universities may differ in their peer group effects. The introduction of a new university induces both symmetric (same peer groups and same number of students) and asymmetric (different peer groups and attendance) equilibria. Our first result is that permitting a new university is unambiguously welfare improving. Most important, a symmetric system maximizes the welfare, thought it provides less quality than the "top" university of the asymmetric system. In particular, the symmetric system widens university participation to the unskilled (less able) individuals and spares the mobility costs to the able individuals that otherwise would need to switch city to study. Although less able individuals are the only benefiting mostly from a symmetric system, their welfare improvement offsets the losses for the other individuals. Our results show that widening participation at the higher education level maximizes the social welfare even when government does not induce universities to compete each other. 


\section{Appendix}

\section{Proof of Lemma 1.}

Proof. Here we show that $\theta_{M}$ is a concave function in $t$ for every $t \in[0,0.5]$, with $0.5 \leq \theta_{M} \leq 0.5858$, and $\theta_{M}=0.5$ for $t=0$ and $t \geq 0.5$, with maximum $\left(\theta_{M}=0.58\right)$ at $t=0.34$. See the figure (1). The average ability of students living in $A$ is $\theta_{A}^{m}=\frac{\int_{0}^{1} \theta d \theta}{\int_{0}^{1} d \theta}=\frac{1}{2}$ while, all students coming from $B$ are such that:

$$
U_{i}^{A}\left(\theta_{M}\right)-t \geq U_{i, u}
$$

then they have the following ability:

$$
\theta \geq \frac{t}{\theta_{M}}
$$

$\theta \in[0,1]$ restricts the analysis to $t \leq \theta_{M}$. The average ability of students coming from $B$ is then:

$$
\theta_{B}^{m}=\frac{\int_{\frac{t}{\theta_{M}}}^{1} \theta d \theta}{\int_{\frac{t}{\theta_{M}}}^{1} d \theta}=\frac{1}{2}\left(\frac{t}{\theta_{M}}+1\right)
$$

By computing the weighted average of $\theta_{A}^{m}$ and $\theta_{B}^{m}, \theta_{M}$ is the result of the following equation:

$$
\theta_{M}=\frac{\frac{1}{2}+\left(1-\frac{t}{\theta_{M}}\right) \theta_{B}^{m}}{1+\left(1-\frac{t}{\theta_{M}}\right)}
$$

that, after rearranging, becomes:

$$
2 \theta_{M}^{3}+\frac{t^{2}}{2}-\theta_{M}^{2}(1+t)=0
$$

the solutions with respect to $t$ are: $t_{1}=\theta_{M}^{2}-\sqrt{\Delta}$ and $t_{2}=\theta_{M}^{2}-\sqrt{\Delta}$, with $\Delta=2 \theta_{M}^{2}-4 \theta_{M}^{3}+4 \theta_{M}^{4}$. See that if $\theta_{M} \geq 0.5, t_{1}$ and $t_{2}$ are both positive. In particular, $\Delta=0$ at $\theta_{M}=0.5858$, but $\Delta$ is a complex number for $\theta_{M}>0.5858$. See the figure 1 where $\theta_{M}$ is on the horizontal axis and the black (red) curve denotes $t_{2}\left(t_{1}\right)$. When $\theta_{M}<0.5, t$ can be greater than $\theta_{M}$ or negative. However, a negative $t$ and $t>\theta_{M}$ are ruled out by assumption. In particular $t>\theta_{M}$ implies that the ability of the "marginal" individual indifferent from going to the monopolist or remaining in $B, \frac{t}{\theta_{M}}$, is greater than 1 , that clearly contradicts the assumption $\theta_{i} \in[0,1]$. In words, if $t>\theta_{M}$ no marginal individual would exist because no individual from $B$ switches to $A$, with the consequence that the average ability in $A$ is only given by the average ability of the individuals living there.

\section{Proof of Proposition 1}


Proof. Each individual living in $A$, with ability $\theta$, chooses the university $B$ if:

$$
U^{A}\left(\theta_{A}^{d}\right) \leq U^{B}\left(\theta_{B}^{d}\right)-t
$$

that gives:

$$
\theta\left(\theta_{A}^{d}-\theta_{B}^{d}\right) \leq-t
$$

an individual living in $B$, instead, goes to the university $A$ if:

$$
U^{A}\left(\theta_{A}^{d}\right)-t \geq U^{B}\left(\theta_{B}^{d}\right)
$$

that gives:

$$
\theta\left(\theta_{A}^{d}-\theta_{B}^{d}\right) \geq t
$$

This enables us to define the peer groups in the two universities as:

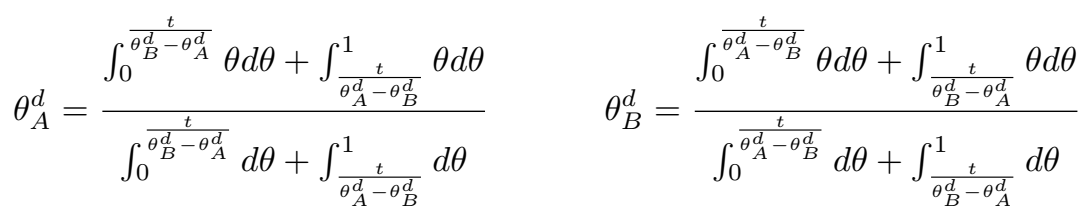

To find the equilibrium values of $\theta_{A}^{d}$ and $\theta_{B}^{d}$ from (16), we need some further specifications on the integrals. The first and the second term of the numerators identify respectively the ability of the students living in that city and those coming from the other. The denominators simply give their mass. The thresholds $\frac{t}{\theta_{B}^{d}-\theta_{A}^{d}}$ and $\frac{t}{\theta_{A}^{d}-\theta_{B}^{d}}$ depend on which university has the higher peer group. Let's check whether symmetric and asymmetric scenarios may characterize Nash equilibria. 1) Asymmetric scenario: $\theta_{A}^{d}>\theta_{B}^{d}$. All individuals living in $A$ choose the university $A$ while individuals living in $B$ choose the university $A$ if their ability satisfies the following condition:

$$
\theta \geq \widehat{\theta}_{B}=\frac{t}{\left(\theta_{A}^{d}-\theta_{B}^{d}\right)}
$$

We then have to put $\frac{t}{\theta_{B}^{d}-\theta_{A}^{d}}=1$ in (16) and by solving the system between the two averages in (16), we find:

$$
\begin{aligned}
& \theta_{A}^{d *}=\frac{1+t}{2}, \theta_{B}^{d *}=\frac{1+t}{4}-\frac{1}{4} \sqrt{t^{2}-6 t+1} \\
& \theta_{A}^{d *}=\frac{1+t}{2}, \theta_{B}^{d * *}=\frac{1+t}{4}+\frac{1}{4} \sqrt{t^{2}-6 t+1}
\end{aligned}
$$

with $-6 t+t^{2}+1>0$ for $0 \leq t \leq 3-2 \sqrt{2}$. Note that we must also satisfy $t<\theta_{A}^{d *}-\theta_{B}^{d *}$ and $t<\theta_{A}^{d *}-\theta_{B}^{\overline{d * *}}$, after a simple substitution we find that this occurs for every $t \leq 3-2 \sqrt{2}$, therefore we conclude that the mobility cost must satisfy $t \leq 3-2 \sqrt{2}$. It is also easy to check that $\theta_{A}^{d *}, \theta_{B}^{d *}, \theta_{B}^{d * *}<1$ for every $0 \leq t \leq 1$. Clearly, there would exist other equilibrium values for $\theta_{B}^{d}, \theta_{A}^{d}$, with $\theta_{B}^{d}>\theta_{A}^{d}$, obtained by inverting the subscripts in (i) in the proposition 1 . The 
only difference is that all individuals living in $B$ choose the university $B$ while individuals living in $A$ choose the university $B$ only if their ability satisfies the condition:

$$
\theta \geq \widehat{\theta}_{A}=\frac{-t}{\left(\theta_{A}^{d}-\theta_{B}^{d}\right)}
$$

where, in the integrals, we must now put $\frac{t}{\theta_{A}^{d}-\theta_{B}^{d}}=1$. The rest of the procedure replicates what we have done for the case $\theta_{A}^{d}>\theta_{B}^{d}$ therefore we omit it. We need a further check to conclude that asymmetric equilibria exist, that is, no student has an incentive to deviate from its equilibrium choice. Since we are in the continuous, the mass of any single student switching university is 0 , therefore the average ability of the university the student is switching to is not affected by his switching. ${ }^{13}$ Let's start by considering a possible deviation for one student that, in equilibrium, goes from $B$ to $A$ (with ability $\left.\theta \geq \frac{t}{\theta_{A}^{d *}-\theta_{B}^{d *}}=\frac{t}{\frac{1}{4}\left(t+\sqrt{-6 t+t^{2}+1}+1\right)}\right)$. He deviates from the asymmetric equilibrium (i) (stays in $B$ ) if the following inequality holds:

$$
U^{A}\left(\theta_{A}^{d *}\right)-t<U^{B}\left(\theta_{B}^{d *}\right)
$$

that gives:

$$
\theta<\frac{4 t}{t+1+\sqrt{-6 t+t^{2}+1}}
$$

Inequality (22) simply defines the ability of any deviating individual. However, see that the deviating student with ability in the range (22) does not belong to the group going from $B$ to $A$ in the asymmetric equilibrium (i) $\left(\theta \geq \frac{4 t}{t+\sqrt{-6 t+t^{2}+1}+1}\right)$. Thus, no deviation occurs. Now we check whether at least one individual remaining in $B$ in the asymmetric equilibrium deviates by switching to $A$. This occurs if:

$$
U^{A}\left(\theta_{A}^{d *}\right)-t>U^{B}\left(\theta_{B}^{d *}\right)
$$

that clearly gives the opposite range of $(22)$ :

$$
\theta>\frac{4 t}{t+1+\sqrt{-6 t+t^{2}+1}}
$$

Again, all individuals with ability in this range do not belong to the group remaining in $B$ in the asymmetric case (with ability $\theta<\frac{4 t}{t+\sqrt{-6 t+t^{2}+1}+1}$ ). Thus we conclude that the asymmetric equilibrium exists. The same result holds for the asymmetric equilibrium (ii).

(2) Symmetric scenario: $\tilde{\theta}_{A}^{d}=\tilde{\theta}_{B}^{d}=\frac{1}{2}$. The symmetric equilibrium is straightforward by construction because when the average abilities equalize then all individuals remain in their city, therefore we have $\tilde{\theta}_{A}^{d}=\tilde{\theta}_{B}^{d}=\frac{1}{2}$ with $\frac{t}{\theta_{B}^{d}-\theta_{A}^{d}}=$ $\frac{t}{\theta_{A}^{d}-\theta_{B}^{d}}=1$. In order to show the existence of the symmetric equilibrium we check

\footnotetext{
${ }^{13}$ This result does not hold if we consider deviations by coalitions of individuals, in which case the mass of the switching students (the coalition) is no longer equal to 0 . This approach would imply the necessity to focus on strong Nash equilibria. We do this further step in the equilibrium refinement in Section 6.
} 
that no student has an incentive to switch university in equilibrium. Again, the mass of any student switching university is 0 , therefore average abilities are unaffected by switching. Consider a student attending $A$ in equilibrium. The condition not to deviate (going to $B$ ) becomes:

$$
U^{A}\left(\tilde{\theta}_{A}^{d}\right)>U^{B}\left(\tilde{\theta}_{B}^{d}\right)-t
$$

that is always satisfied. The same argument holds for students attending university $B$.

\section{Proof of Lemma 2}

Proof. The second part of the Lemma 2 follows directly from Lemma 1 and the values of $\tilde{\theta}_{A}^{d}$ and $\tilde{\theta}_{B}^{d}$ in the Proposition 1. To show the first part we start from (11) and define the function $F(\theta)=2 \theta^{3}+\frac{t^{2}}{2}-\theta^{2}(1+t)$, reminding that $F\left(\theta_{M}\right)=0$ with $F($.$) increasing (decreasing) in \theta$ for $\theta \geq \frac{1}{3} t+\frac{1}{3}\left(\theta<\frac{1}{3} t+\frac{1}{3}\right)$. Given this result, by plugging $\theta_{A}^{d *}$ into $F(\theta)$ we obtain $F\left(\theta_{A}^{d *}\right)=\frac{1}{2} t^{2}>0$, hence we have $\theta_{A}^{d *} \geq \theta_{M}$ under $\theta_{M} \geq \frac{1}{3} t+\frac{1}{3}$ and $\theta_{A}^{d *} \geq \frac{1}{3} t+\frac{1}{3}$. Proposition 1 and Lemma 1 in fact restrict the mobility cost to the range $t \in(0,3-2 \sqrt{2}]$ that makes the threshold $\frac{1}{3} t+\frac{1}{3}$ vary between $\frac{1}{3}$ and 0.39052 . This is enough to show that condition $\theta \geq \frac{1}{3} t+\frac{1}{3}$ is always satisfied because we have $0.5 \leq \theta_{M} \leq 0.5858$ and $0.5 \leq \theta_{A}^{*} \leq 0.5858$. We may also see that: a) $\theta_{A}^{d *}=\theta_{M}=0.5$ for $t=0$, and b) $\theta_{M}=0.5625$ and $\theta_{A}^{d *}=0.5858$ for $t=3-2 \sqrt{2}$. The same procedure gives $F\left(\theta_{B}^{d *}\right)<0$ and $F\left(\theta_{B}^{d * *}\right)<0$ that imply respectively $\theta_{B}^{d *}<\theta_{M}$ and $\theta_{B}^{d * *}<\theta_{M}$.

\section{Proof of Proposition 2.}

Proof. 1) Monopoly vs symmetric universities: $W_{a}>W_{M}$. We remind that the mobility cost such that the asymmetric equilibria exist is $t \in$ $(0,3-2 \sqrt{2}$. The result in Lemma 2 implies that individuals remaining in the university $A$ even in the asymmetric equilibrium are better off because they receive a higher peer group without paying any mobility cost. Individuals from $B$ that would not go to the monopolist but only attend the new university $B$, are also better off because they get skilled without costs as well. Now, if there exists a group of individuals from $B$ attending the monopolist but also preferring the university $B$ in the asymmetric equilibrium, then these students are better off after the introduction of the university $B$ because they would have preferred $B$ even to the monopolist since $\theta_{A}^{d *}>\theta_{M}$. 2) Monopoly vs symmetric universities: $W_{S}>W_{M}$. Since the symmetric equilibrium exists for any $t$, we focus on $t \in(0,0.5)^{14}$. The values of $W_{M}$ and $W_{S}$ are: ${ }^{15}$

$$
W_{M}=\int_{0}^{1} U^{M}\left(\theta_{M}\right) d \theta+\int_{\frac{t}{\theta_{M}}}^{1}\left(U^{M}\left(\theta_{M}\right)-t\right) d \theta+\int_{0}^{\frac{t}{\theta_{M}}} U_{u} d \theta
$$

\footnotetext{
${ }^{14}$ We remind that, by Proposition 1 , we have $\theta_{M}=0.5$ for every $t \geq 0.5$

${ }^{15}$ We rule out the subscript $i$ to ease the analysis.
} 


$$
W_{S}=\int_{0}^{1} U^{A}\left(\tilde{\theta}_{A}^{d}\right) d \theta+\int_{0}^{1} U^{B}\left(\tilde{\theta}_{B}^{d}\right) d \theta=1.5
$$

Where the first two integrals in $W_{M}$ include the utilities of individuals studying in $A$, because living there (the first) or coming from $B$ (the second). The last term defines individuals left unskilled in $B$. We find that $W_{S} \geq W_{M}$ for every $\theta_{M}-\sqrt{\theta_{M}\left(1-\theta_{M}\right)}<t$, that holds in our range of $t$. To show this result we simply take the values $t_{1}$ and $t_{2}$ from the proof of the Proposition 1 , and see that $\theta_{M}-\sqrt{\theta_{M}\left(1-\theta_{M}\right)}<t_{1}$ and $\theta_{M}-\sqrt{\theta_{M}\left(1-\theta_{M}\right)}<t_{2}$ for every $0.5 \leq \theta_{M} \leq 0.5858$. 3) Symmetric vs asymmetric universities: $W_{S}>W_{a}$. Let us define $W_{a}$ as the welfare in the asymmetric equilibrium (i), with:

$$
W_{a}=\int_{0}^{1} U^{A}\left(\theta_{A}^{d *}\right) d \theta+\int_{\frac{t}{\theta_{A}^{d *}-\theta_{B}^{d *}}}^{1}\left(U^{A}\left(\theta_{A}^{d *}\right)-t\right) d \theta+\int_{0}^{\overline{\theta_{A}^{d *}-\theta_{B}^{d *}}} U^{B}\left(\theta_{B}^{d *}\right) d \theta
$$

The first two terms in $W_{a}$ represent the utilities of individuals studying in $A$, because living there (the first) or coming from $B$ (the second). The last term includes the utilities of the less able skilled in $B$. After substituting for $\theta_{A}^{d *}$ and

$\theta_{B}^{d *}$ into (28), we find $W_{s} \geq W_{a}$ for every $t \leq 3-2 \sqrt{2}$. The same result holds for the asymmetric equilibrium (ii). It is straightforward to see that, in line with the footnote (10), for $t=0$ and $t=0.5$ we would have $W_{a}=W_{M}$ and $W_{S}>W_{M}$ respectively.

\section{Proof of Proposition 3.}

Proof. We check whether there exists any coalition deviating from the symmetric equilibrium. Let us define a coalition composed of students with the lowest ability equal to $a$ and with mass $1-a$. We also define an optimal coalition as a group of students with ability $\theta \in\left[a^{*}, 1\right]$, where $a^{*}$ is the ability of the least able student maximizing the gain the coalition receives when deviating from the equilibrium strategy. We start by considering the coalition composed of students that in equilibrium are in $B$. The gain from the deviation is given by the peer group the coalition will find in the new university (denoted here by $\widehat{\theta}_{A}$ ). If a coalition of mass $1-a$ switches to the university $A$, the new peer group in $A$ becomes:

$$
\widehat{\theta}_{A}=\frac{\int_{0}^{1} \theta d \theta+\int_{a}^{1} \theta d \theta}{\int_{0}^{1} d \theta+\int_{a}^{1} d \theta}=\frac{\frac{1}{2} a^{2}-1}{a-2}
$$

the first term in the numerator represents the students already in $A$, whereas the second term identifies the coalition of students coming from $B$. The condition for this coalition not to deviate is:

$$
U^{B}\left(\tilde{\theta}_{B}^{d}\right) \geq U^{A}\left(\widehat{\theta}_{A}^{*}\right)-t
$$


where the left hand side is the utility from remaining in $B$, while the right hand side is the utility when switching university, computed at $\widehat{\theta}_{A}^{*}=\widehat{\theta}_{A}\left(a^{*}\right)$. Where $a^{*}$ is

$$
a^{*}=\underset{a}{\arg \max } U^{A}\left(\widehat{\theta}_{A}\right)-\left(t+U^{B}\left(\tilde{\theta}_{B}^{d}\right)\right)=0.5858
$$

We obtain $\widehat{\theta}_{A}^{*}=0.5858$ with the mass of this coalition equal to 0.4142 . To show that the coalition as a whole does not deviate it is sufficient to show that (30) holds for the ablest individual of the coalition $(\theta=1)$ because he has the highest benefit from the deviation. ${ }^{16}$ By simply substituting $\theta=1$ into (30) we see that it holds for every $t>0.086$. The same results hold for the coalition of students going from $A$ to $B$.

\section{Proof of Proposition 4}

Proof. Consider the peer groups of the asymmetric equilibria ((i) and (ii)) in the Proposition 2. To show that the asymmetric equilibria are not strong Nash it is enough to show the existence of at least one deviating coalition. Consider the ad hoc coalition composed of individuals that, in equilibrium, go from $B$ to $A$ (with $\theta \in[a, 1]$ and $a=\frac{t}{\theta_{A}^{d *}-\theta_{B}^{d *}}$ ), such that the peer group they receive in $B$, once deviated, is just $\tilde{\theta}_{B}^{d}=\frac{1}{2}$. The condition for the deviation to be profitable is:

$$
U^{B}\left(\widetilde{\theta}_{B}^{d}\right) \geq U^{A}\left(\theta_{A}^{d *}\right)-t
$$

that always holds. This is enough to show that the asymmetric equilibria are never Strong Nash.

\section{References}

[1] Arcidiacono, P. Foster G., Goodpaster N., Kinsler J., 2011. Estimating spillovers using panel data, with an application to the classroom. mimeo

[2] Arcidiacono, P., Nicholson, S., 2005. Peer effects in medical schools. Journal of Public Economics 89, 327-350.

[3] Banerjee, A.V., Newman, A.F., 1993. Occupational choice and the process of development. Journal of Political Economy 101, 274-298.

[4] Brunello G., De Paola M., Scoppa V., 2010. Peer effects in higher education: does the field of study matter? Economic Inquiry 48, 621-634.

[5] Daraio C., et al. 2010. The European university landscape: a micro characterization based on evidence from the Aquameth project. Research Policy 40, 148-164.

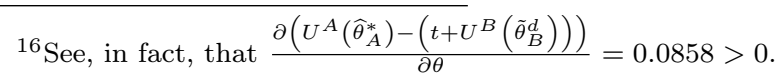


[6] De Paola M., Scoppa, V., 2010. Peer group effects on the academic performance of Italian students. Applied Economics 42, 2203-2215.

[7] De Fraja, G., Iossa, E., 2002. Competition among universities and the emergence of the elite institution. Bulletin of Economic Research 54, 275294.

[8] De Giorgi G., Pellizzari M., Redaelli S., 2010. Identification of social interactions through partially overlapping peer groups. American Economic Journal: applied economics 2, 241-275.

[9] Del Rey, E., 2001. Teaching versus research: a model of state university competition. Journal of Urban Economics 49, 356-373.

[10] Del Rey, E., Wauthy, G., 2006. Mencion De Calidad: reducing inefficiencies in higher education markets when there are network externalities. Investigationes Economicas XXX, 89-115.

[11] Ding, W., Lehrer, S.F., 2007. Do peers affect student achievement in China's secondary schools? Review of Economics and Statistics 89, 300312 .

[12] Epple, D., Romano, R., 2008. Educational vouchers and cream skimming. International Economic Review 49, 1395-1435.

[13] Frenette, M., 2004. Access to college and university: does distance to school matter? Canadian Public Policy 30, 427-443.

[14] Frenette, M., 2005. Too far to go on? Distance to school and university participation. Education Economics 14, 31-58.

[15] Frenette, M., 2009. Do universities benefit local youth? Evidence from the creation of new universities. Economics of Education Review 28, 318-328.

[16] Galor, O., Zeira, J., 1993. Income distribution and macroeconomics. Review of Economic Studies 60, 35-52.

[17] Gautier, A., Wauthy, X., 2007. Teaching versus research: a multi-tasking approach to multi-department universities. European Economic Review 51, 273-295.

[18] Gibbons, S., Vignoles, A., 2009. Access, choice and participation in higher education, CEE DP 101.

[19] Grazzini, L., Luporini A., Petretto A., 2011. Competition between State Universities. CESifo Working Paper Series No. 3373.

[20] Higher education funding council for England (HEFCE). A new university challenge: unlocking Britain's talent (2008). 2008/27. http://webarchive.nationalarchives.gov.uk/+/http://www.dius.gov.uk/policy/documents/universitychallenge.pdf 
[21] Hoxby, C.M., Weingart, G., 2005. Taking Race out of the equation: school reassignment and the structure of peer effects. Unpublished manuscript.

[22] Kang, C., 2007. Classroom peer effects and academic achievement: quasirandomization evidence from South Korea. Journal of Urban Economics 61, 458-495.

[23] Kenyon, S., 2010. Widening participation: a role for transport? UK higher education policy and mobility related educational exclusion. Widening Participation and Lifelong Learning 2.

[24] Maoz, Y.D., Moav, O., 1999. Intergenerational Mobility and the Process of Development. Economic Journal 109, 677-697.

[25] Mookherjee, D., et al. (2010a). Aspirations, segregation and occupational choice. Journal of the European Economic Association 8,139-168.

[26] Mookherjee, D., et al. (2010b). Social interactions and segregation in skill accumulation. Journal of the European Economic Association 8, 1-13.

[27] Mookherjee, D., Ray, D., 2003. Persistent Inequality. Review of Economic Studies 70, 369-393.

[28] OECD 2006. Thematic review of tertiary education. Country background for Sweden. Report prepared by the Swedish National Agency for Higher Education.

[29] Ost, B., 2010. The role of peers and grades in determining major persistence in the sciences. Economics of Education Review 29, 923-934.

[30] Sá, C., et al. 2006. Does accessibility to higher education matter? Choice behavior of high school graduates in the Netherlands. Spatial Economic Analysis 1, 155-174.

[31] Sacerdote, B., 2001. Peer effects with random assignment: results for Dartmouth roommates. Quarterly Journal of Economics, 116, 681-704.

[32] Spiess, C.K, Wrohlich, K., 2010. Does distance determine who attends a university in Germany? Economics of Education Review 29, 470-479.

[33] Zimmerman, D., 2003. Peer effects in academic outcomes: evidence from a natural experiment. Review of Economics and Statistics 85, 9-23. 


\section{Recent titles \\ CORE Discussion Papers}

2012/3. Jeroen K. ROMBOUTS, Lars STENTOFT and Francesco VIOLANTE. The value of multivariate model sophistication: An application to pricing Dow Jones Industrial Average options.

2012/4. Aitor CALO-BLANCO. Responsibility, freedom, and forgiveness in health care.

2012/5. Pierre PESTIEAU and Grégory PONTHIERE. The public economics of increasing longevity.

2012/6. Thierry BRECHET and Guy MEUNIER. Are clean technology and environmental quality conflicting policy goals?

2012/7. Jens L. HOUGAARD, Juan D. MORENO-TERNERO and Lars P. ØSTERDAL. A new axiomatic approach to the evaluation of population health.

2012/8. Kirill BORISSOV, Thierry BRECHET and Stéphane LAMBRECHT. Environmental maintenance in a dynamic model with heterogenous agents.

2012/9. Ken-Ichi SHIMOMURA and Jacques-François THISSE. Competition among the big and the small.

2012/10. Pierre PESTIEAU and Grégory PONTHIERE. Optimal lifecycle fertility in a Barro-Becker economy.

2012/11. Catherine KRIER, Michel MOUCHART and Abderrahim OULHAJ. Neural modelling of ranking data with an application to stated preference data.

2012/12. Matthew O. JACKSON and Dunia LOPEZ-PINTADO. Diffusion and contagion in networks with heterogeneous agents and homophily.

2012/13. Claude D'ASPREMONT, Rodolphe DOS SANTOS FERREIRA and Jacques THEPOT. Hawks and doves in segmented markets: A formal approach to competitive aggressiveness.

2012/14. Claude D'ASPREMONT and Rodolphe DOS SANTOS FERREIRA. Household behavior and individual autonomy: An extended Lindahl mechanism.

2012/15. Dirk VAN DE GAER, Joost VANDENBOSSCHE and José Luis FIGUEROA. Children's health opportunities and project evaluation: Mexico's Oportunidades program.

2012/16. Giacomo VALLETTA. Health, fairness and taxation.

2012/17. Chiara CANTA and Pierre PESTIEAU. Long term care insurance and family norms.

2012/18. David DE LA CROIX and Fabio MARIANI. From polygyny to serial monogamy: a unified theory of marriage institutions.

2012/19. Carl GAIGNE, Stéphane RIOU and Jacques-François THISSE. Are compact cities environmentally friendly?

2012/20. Jean-François CARPANTIER and Besik SAMKHARADZE. The asymmetric commodity inventory effect on the optimal hedge ratio.

2012/21. Concetta MENDOLICCHIO, Dimitri PAOLINI and Tito PIETRA. Asymmetric information and overeducation.

2012/22. Tom TRUYTS. Stochastic signaling: Information substitutes and complements.

2012/23. Pierre DEHEZ and Samuel FEREY. How to share joint liability: A cooperative game approach.

2012/24. Pilar GARCIA-GOMEZ, Erik SCHOKKAERT, Tom VAN OURTI and Teresa BAGO D'UVA. Inequity in the face of death.

2012/25. Christian HAEDO and Michel MOUCHART. A stochastic independence approach for different measures of concentration and specialization.

2012/26. Xavier RAMOS and Dirk VAN DE GAER. Empirical approaches to inequality of opportunity: principles, measures, and evidence.

2012/27. Jacques H. DRĖZE and Erik SCHOKKAERT. Arrow's theorem of the deductible : moral hazard and stop-loss in health insurance.

2012/28 Luc BAUWENS and Giuseppe STORTI. Computationally efficient inference procedures for vast dimensional realized covariance models.

2012/29. Pierre DEHEZ. Incomplete-markets economies: The seminar work of Diamond, Drèze and Radner.

2012/30 Helmuth CREMER, Pierre PESTIEAU and Grégory PONTHIÈRE. The economics of longterm care: a survey. 


\section{Recent titles}

\section{CORE Discussion Papers - continued}

2012/31 Mathieu VAN VYVE, Laurence A. WOLSEY and Hande YAMAN. Relaxations for two-level multi-item lot-sizing problem.

2012/32 Jean-François MERTENS and Anna RUBINCHIK. Equilibria in an overlapping generations model with transfer policies and exogenous growth.

2012/33 Jean-François MERTENS and Anna RUBINCHIK. Pareto optimality of the golden rule equilibrium in an overlapping generations model with production and transfers.

2012/34 Hélène LATZER and Florian MAYNERIS. Income distribution and vertical comparative advantage. Theory and evidence.

2012/35 Pascal MOSSAY and Takatoshi TABUCHI. Preferential trade agreements harm third countries.

2012/36 Aitor CALO-BLANCO. The compensation problem with fresh starts.

2012/37 Jean-François CARPANTIER and Arnaud DUFAYS. Commodities volatility and the theory of storage.

2012/38 Jean-François CARPANTIER and Christelle SAPATA. Unfair inequalities in France: A regional comparison.

2012/39 Shui-Ki WAN, Shin-Huei WANG and Chi-Keung WOO. Total tourist arrival forecast: aggregation vs. disaggregation.

2012/40 Thierry BRECHET, Yann MENIERE and Pierre M. PICARD. The clean development mechanism in a global carbon market.

2012/41 Nikolaos GEORGANTZIS, Rafael MONER-COLONQUES, Vicente ORTS and José J. SEMPERE-MONERRIS. Theoretical and experimental insights on firms' internationalization decisions under uncertainty.

2012/42 Berardino CESI and Dimitri PAOLINI. Peer group and distance: when widening university participation is better.

\section{Books}

G. DURANTON, Ph. MARTIN, Th. MAYER and F. MAYNERIS (2010), The economics of clusters Lessons from the French experience. Oxford University Press.

J. HINDRIKS and I. VAN DE CLOOT (2011), Notre pension en heritage. Itinera Institute.

M. FLEURBAEY and F. MANIQUET (2011), A theory of fairness and social welfare. Cambridge University Press.

V. GINSBURGH and S. WEBER (2011), How many languages make sense? The economics of linguistic diversity. Princeton University Press.

I. THOMAS, D. VANNESTE and X. QUERRIAU (2011), Atlas de Belgique - Tome 4 Habitat. Academia Press.

W. GAERTNER and E. SCHOKKAERT (2012), Empirical social choice. Cambridge University Press.

L. BAUWENS, Ch. HAFNER and S. LAURENT (2012), Handbook of volatility models and their applications. Wiley.

J-C. PRAGER and J. THISSE (2012), Economic geography and the unequal development of regions. Routledge.

M. FLEURBAEY and F. MANIQUET (2012), Equality of opportunity: the economics of responsibility. World Scientific.

J. HINDRIKS (2012), Gestion publique. De Boeck.

\section{CORE Lecture Series}

R. AMIR (2002), Supermodularity and complementarity in economics.

R. WEISMANTEL (2006), Lectures on mixed nonlinear programming.

A. SHAPIRO (2010), Stochastic programming: modeling and theory. 